\title{
Dry matter accumulation and nutritive value of winter forage crops sown in Canterbury on different dates.
}

\begin{abstract}
Supplementary forage crops are used in New Zealand to overcome feed shortages during winter and early spring. The objective of this study was to maximize annual dry matter (DM) yield by optimizing sowing and harvest dates. Forage crop options include faba bean, oats and Italian ryegrass. These were sown on five dates in the autumn and winter of 2008 and on three sowing dates in the autumn of 2009. The maximum total DM ranged from 4420 to $26,310 \mathrm{~kg} \mathrm{ha}-1$ across all species and sowing dates for both seasons. Oats yielded the highest maximum total DM in both years. The quality analysis showed oats sown in early March and harvested at the end of August attained herbage metabolisable energy (ME) of $11.5 \mathrm{MJ} \mathrm{kg}-1$ DM and high total ME per ha which was suitable for the lactation of dairy cows. Thus, oats was the beneficial alternative forage crop for farmers to choose. Faba bean had lowest maximum total DM yield compared with oats and Italian ryegrass in the first season; however, faba bean had higher maximum total DM compared with Italian ryegrass but lower than oats and faba bean-oat intercrop in the second season. Faba bean sown from early March to midApril and harvested at the end of November attained a herbage nitrogen $(\mathrm{N})$ content of more than $2.4 \%$ and had the highest total $\mathrm{N}$ uptake per ha compared with oats and Italian ryegrass at $2.4 \%$ of herbage $\mathrm{N}$.
\end{abstract}

Keyword: Avena sativa; Dry matter yield; Harvest date; Lolium multiflorum; Nutritive value; Sowing date; Vicia faba. 